$\begin{gathered}\text { Revista do Departamento de Geografia } \\ \text { Universidade de São Paulo } \\ \text { www.revistas.usp.br/rdg }\end{gathered}$
Volume Especial - XVII SBGFA / I CNGF (2017)
ISSN 2236-2878

\title{
Aspectos da Tectônica Ativa em Bordas Cratônicas: Interpretações com Base em Dados Geomorfométricos na Região das Altas Cristas Quartzíticas da Zona da Mata Mineira
}

\section{Aspects of Active Tectonics on The Cratonic Borders: Interpretations Based on Geomorphometric Data in the High Ridges Quartzitic Regionof the Zona da Mata Mineira}

\author{
Felipe Rodrigues Silva \\ Universidade Federal de Juiz de Fora \\ flip.867@gmail.com \\ Roberto Marques Neto \\ Universidade Federal de Juiz de Fora \\ roberto.marques@ufjf.edu.br \\ Juliana Alves Moreira \\ Universidade Federal de Juiz de Fora \\ julianaalves22@gmail.com \\ Elver Lonie Nunes Rodrigues \\ Universidade Federal de Juiz de Fora \\ elverloner@gmail.com
}

\begin{abstract}
By the last years, the areas in direct influence of the southeast brazilian continental rift has been a target for the studies about the neotectonic theme, in an integrated way to the works that has been carried out in other regions of the country. In this present opportunity are shown the results coming from the application of morphometric techniques for the differentiation between passive and active controls in the high ridges quartzitic of Zona da Mata Mineira region, for which more specific studies are still lacking. With the integrated application between the Relationship Slope $x$ Extension of the channel $(R D E)$ index and the measurement and cartographic representation of the base surfaces, associated to field control and interpretation of remote sensing products, active morphotectonic control was verified in the evolution of the relief, and that has been engendering substantial reorganizations in surface forms and processes.
\end{abstract}

Keywords: Anomaly; Base Surfaces; Tectonic Control; Quartzitic Scarps.

Palavras-chave: Anomalia; Superfícies de Base; Controle Tectônico; Escarpas Quartizíticas. 


\section{INTRODUÇÃO}

A investigação da tectônica cenozoica no sudeste brasileiro tem como referência permanente o trabalho de Riccomini (1989) a respeito do rifte continental do sudeste do Brasil, importante feição geotectônica que envolve cinco fases evolutivas, também citadas por Riccomoni et al. (2004) e por Silva e Mello (2011), quais sejam: 1) Eoceno-Oligoceno - distensão NNW-SSE em função do basculamento da bacia de Santos e consequente formação de depressão contínua pela reativação de antigas falhas de idade brasiliana; 2) Neógeno - transcorrência sinistral E-W (primeira fase de deformação do rifte), com distensão NW-SE e compressão NE-SW; 3) Pleistoceno/Holoceno - transcorrência dextral E-W e compressão NW-SE; 4) Holoceno distensão NW-SE; 5) Holoceno e período subatual - compressão E-W com geração de juntas ENE e WNW, campo de esforços que perdura até o presente.

Doravante, diversos trabalhos focaram a evolução cenozoica do relevo com ênfase ou grande apreço em seus aspectos morfotectônicos (SAADI, 1991; GONTIJO, 1999; HIRUMA E RICCOMINI, 1999; SANTOS, 1999; FACINCANI, 2000; ETCHEBEHERE, 2000; FERREIRA, 2001; RIBEIRO, 2003; CHIESSI, 2004; MORALES, 2005; SILVA E MELLO, 2011; MARQUES NETO, 2012), entre outros.

A região das cristas quartzíticas da Zona da Mata Mineira figura como o derradeiro controle NE da Mantiqueira Meridional (sensu GATTO et al., 1983), estabelecendo contato com os rebordos erosivos da Mantiqueira Setentrional e tectônico com as baixas cristas e morrarias da Zona da Mata Mineira. Inscrevemse, portanto, na área de influência do rifte continental, respondendo ativamente às solicitações tectônicas cenozoicas que tem acometido os cinturões moveis brasilianos, hipótese esta que cimenta o presente paper, ainda que estudos mais específicos não tenham sido ainda dispensados a estas cristas quartzíticas de eloquente expressão na paisagem regional. Especificamente, fica assumido como objetivo levar a efeito, no âmbito da área supramencionada, a apresentação e discussão dos resultados referentes à aplicação de técnicas geomorfométricas voltadas à interpretação de aspectos morfoestruturais e morfotectônicos, e que, em conjunto a outras abordagens, vem subsidiando as investigações acerca da evolução do relevo regional.

\section{MATERIAIS E MÉTODOS}

Algumas técnicas morfométricas têm sido flagrantemente utilizadas nos estudos pautados no campo temático da neotectônica, com resultados auspiciosos na diferenciação entre contextos caracterizados por controle estrutural e situações nas quais a tectônica é eminentemente ativa na evolução do relevo e da drenagem. Entre os parâmetros geomorfométricos de utilização corrente, foram incorporados aos resultados aqui apresentados o índice de Hack (HACK, 1973), difundido no Brasil por Etchebehere (2000, 2004) sob a designação Relação Declividade x Extensão do Canal (RDE), alinhavado à interpretação das superfícies de base (Ferrari, 1984), técnica que admite correlações com o índice geomórfico mensurado.

$\mathrm{O}$ índice RDE permite a averiguação das variações no declive do canal ao longo de seu percurso, e pode ser obtido pela Equação 1:

$$
\mathrm{RDE}=(\Delta \mathrm{H} / \Delta \mathrm{L}) . \mathrm{L} \quad(\text { Equação } 1)
$$

Onde

$\Delta \mathrm{H}=$ diferença altimétrica entre dois pontos extremos de um segmento ao longo do curso d'água;

$\Delta \mathrm{L}=$ projeção horizontal da extensão do referido segmento;

$\mathrm{L}=$ comprimento total do curso d'água a montante do ponto para o qual o RDE foi mensurado.

Primeiramente são calculados os valores nos trechos espaçados por desníveis de 20 metros, e os valores mensurados para cada trecho são relacionados com o RDE total, obtido mediante relação entre a amplitude altimétrica total e o logarítmo do comprimento total do vale, conforme a Equação 2:

Onde

$$
\mathrm{RDE} \text { total }=\Delta \mathrm{H} / \log \mathrm{L} \quad(\text { Equação 2) }
$$

$\Delta \mathrm{H}=$ diferença altimétrica entre dois pontos extremos de um segmento ao longo do curso d'água; $\mathrm{L}=$ comprimento total do curso d'água a montante do ponto para o qual o RDE foi mensurado. 
Os valores derivados de tal relação foram qualificados em consonância a proposição de Seeber e Gornitz (1983), segundo a qual os resultados compreendidos entre 0 e 2 não representam anomalia, aqueles entre 2 e 10 representativas anomalias de segunda ordem e os acima de 10 de anomalias de terceira ordem. Foram considerados como comportamentos anômalos aqueles que comungaram com outras evidências de cunho morfotectônico, como desvios e encaixamentos abruptos, abertura de alvéolos de retenção sedimentar, etc., em detrimento dos controles majoritariamente estruturais, como extensões de canais dissecando vertentes de cristas, onde a energia da corrente é presumivelmente elevada.

As superfícies de base foram obtidas em consonância aos procedimentos levados a efeito por Salvador \& Pimentel (2009). São representadas cartograficamente a partir de isobases que correspondem a uma superfície hipotética determinada pela intersecção entre a rede de drenagem de ordem similar com a superfície erosiva associada à reorganização da rede hidrográfica, fornecendo valiosas informações acerca do quadro tectono-erosivo mais recente (JAIN, 1984). O mapa com as isobases, editado na escala de 1:50.000, foi obtido com o emprego do software ArcGIS, ambiente no qual foi extraída a rede de drenagem do modelo digital de elevação (MDE), hierarquizada segundo Strahler (1952). Doravante, foram selecionados os canais de $2^{\mathrm{a}}$ ordem, convertidos ao formato raster com valor 1; posteriormente, tal arquivo foi combinado com o MDE através de multiplicação, obtendo-se assim as altitudes locais. O passo seguinte consistiu na vetorização do arquivo para geração de outro arquivo de pontos cotados, que foram gridados através de interpolação pelo método IDW.

Subsequentemente foram averiguadas as correlações entre o mapa de superfícies de base e os resultados de RDE, interpretando, a partir desses termos e do controle de campo, o significado morfoestrutural e/ou morfotectônico das rupturas nos perfis longitudinais dos canais. Os estudos foram ainda subsidiados pela interpretação da base geológica, compilada a partir dos mapeamentos de Heinek et al. (1991) e Soares et al. (2002), de imagens de radar SRTM em relevo sombreado geradas em quatro ângulos de iluminação azimutal $\left(45^{\circ}, 90^{\circ}, 315^{\circ}\right.$ e $\left.360^{\circ}\right)$, bem como das bases planialtimétricas na escala de 1:50.000, a mesma que serviu de base para o cálculo de RDE e para a geração do mapa de superfícies de base.

\section{ÁREA DE ESTUDO}

As altas cristas quartzíticas da Zona da Mata Mineira figuram como um compartimento morfoestrutural definido pelas serranias festonadas posicionadas no limite NNE da Mantiqueira Meridional (sensu GATTO et al., 1983), sustentadas por quartzitos intercalados a xistos e gnaisses pertencentes ao Grupo Andrelândia, além de significativo corpo ortognáissico em domínios altimontanos, conforme informado nos mapeamentos levados a efeito por Heinek et al. (1991) e Soares et al. (2003) (Figura 1). Tal compartimento se inscreve nos terrenos sob a influência do sistema rifte continental do sudeste do Brasil (RICCOMINI, 1989), com reativação de falhas pré-cambrianas ao longo do Cretáceo-Paleógeno e soerguimento generalizado da fachada atlântica do Brasil Sudeste em regime epirogenético.

O conjunto das altas cristas quartzíticas é dado pelas serras do Ibitipoca, Negra e de Lima Duarte, estruturas estas ladeadas por alinhamentos de menor elevação que não partilharam da área trabalhada. Apresentam aspecto de superfícies estruturais, preservadas em função da resistência das litologias quartzíticas à alteração química, ainda que deformadas tectonicamente durante o Cenozoico. Os fundos dos vales adjacentes às cristas, por seu turno, estão vinculados à ocorrência de xistos, rochas mais tenras e profundamente alteradas. Diferentemente do restante do horst contínuo da Mantiqueira Meridional, as cristas quartzíticas não apresentam drenagem dual conectada a dois níveis de base distintos, mas estão condicionadas ao nível geral do Oceano Atlântico, com nível de base local imposto pelo rio do Peixe no festonamento que exerce em tais estruturas.

A resistência dos quartzitos aos processos geoquímicos intensos do meio tropical repercute na existência de solos rasos e ricos em minerais primários ao longo das cristas, ocorrendo Neossolo Litólico e Neossolo Regolítico recorrentemente atacados por processos de arenização. O escoamento superficial significativamente acelerado que perpassa as vertentes declivosas tem encontrado relativa facilidade em remobilizar coberturas arenosas ao longo das fitofisionomias abertas em campos rupestres, sobretudo nos setores onde a cobertura vegetal é dominantemente herbácea ou esparsa demais para conter a acomodação em superfície das areias que se encontram em franca remobilização no sistema. Acumulações coluviais se organizam nos degraus reafeiçoados de baixas encostas, onde a estrutura superficial da paisagem é caracterizada por solum mais espesso, em parte submetido à pedogênese latossólica, fundamentalmente nos contextos sob a influência dos corpos rochosos gnáissicos e xistosos. Sobre tais materiais eclodem formações florestais em Floresta Estacional Semidecidual, que medra naturalmente quando o substrato se faz tolerante para as formas macrofanerófitas. 
Atualmente, tanto as fitofisionomias florestais como os campos rupestres das cristas quartzíticas encontram-se francamente alterados ou substituídos por pastos e silvicultura de Eucalyptus, principalmente. Restam as formações vegetais nativas nos flancos mais declivosos da Serra do Ibitipoca e Negra, bem como nas áreas protegidas do Parque Estadual do Ibitipoca, unidade de conservação de proteção integral que detém uma amostra da riqueza de habitats, espécies e geodiversidade inerentes ao sistema geomorfológico em lume quando próximo de suas estruturas originais.

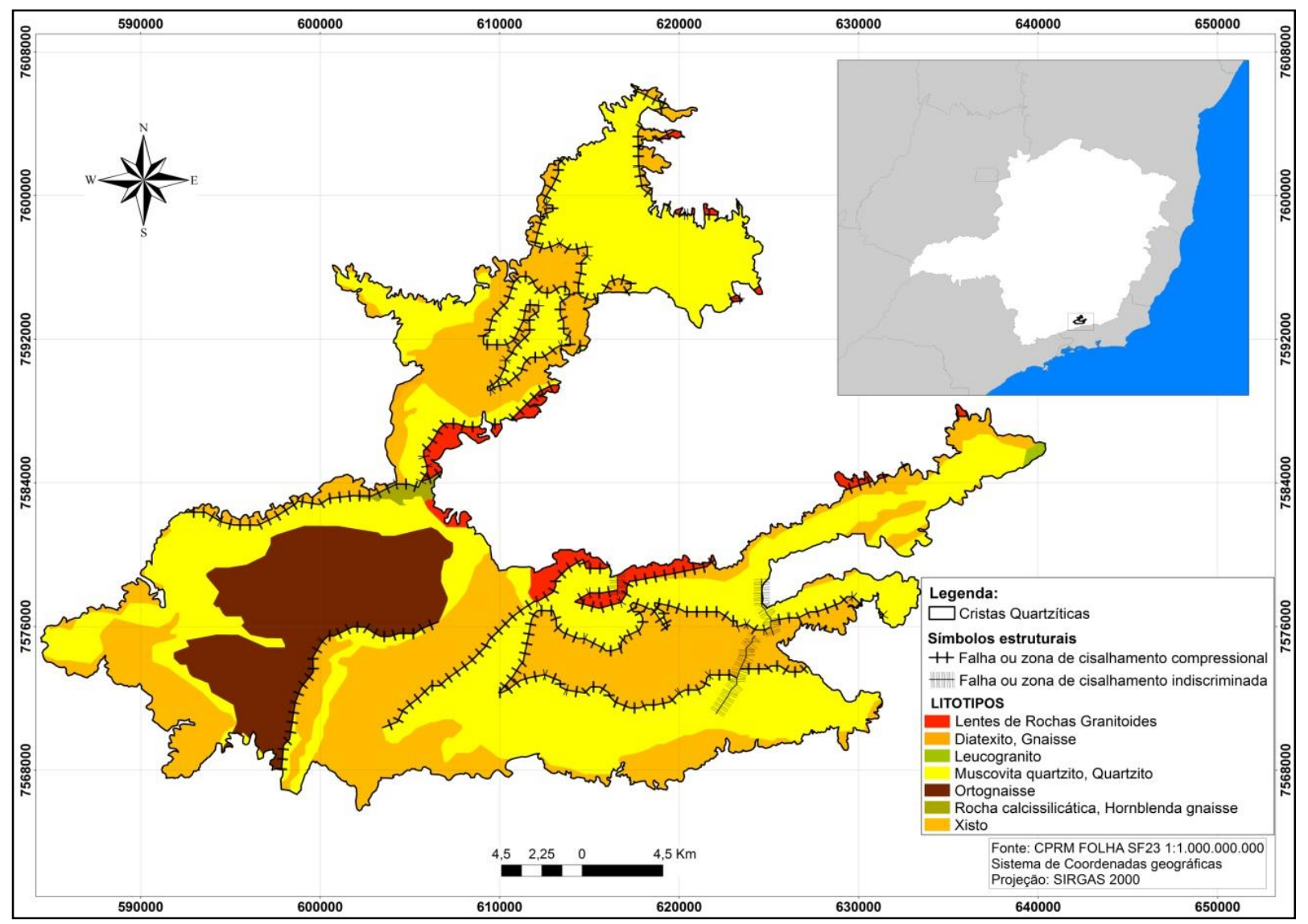

Figura 1. Localização da área de estudo e sua base geológica.

\section{RESULTADOS}

A área de estudo computou catorze canais, hierarquizados a partir da quarta ordem e com extensão superior a 5000 metros, que dissecam as cristas em demanda aos níveis de base locais (Tabela 1). A Figura 2 representa o perfil longitudinal dos catorze canais selecionados para investigação, com as anomalias e zonas de anomalias devidamente apontadas, permitindo a visualização de tais comportamentos ao longo dos canais.

O significado das anomalias encontradas, em grande medida, é relacionável ao controle morfotectônico, ainda que alguns valores elevados indiquem também um arranjo da drenagem às estruturas preexistentes, tal como ocorre com os canais de alto curso, que dissecam as vertentes íngremes das cristas quartzíticas. Exemplo disso é o ribeirão Rosa Gomes, cuja primeiro valor anômalo encontrado reflete segmento de corrente com energia elevada em relevo escarpado. No entanto, rupturas mais bruscas são verificadas no corte epigênico que o canal promove na lasca quartzítica soerguida e na abertura de planície de inundação, que, abruptamente gerada após significativa extensão em encaixamento, sugere a existência de um bloco em subsidência. 
Tabela 1: Anomalias de drenagem detectadas para os canais fluviais hierarquizados a partir da $4^{\circ}$ ordem para a área de estudo.

\begin{tabular}{|c|c|c|c|c|c|}
\hline CANAL & $\begin{array}{c}\text { AMPLITU } \\
\text { DE TOTAL } \\
(\mathrm{m})\end{array}$ & $\begin{array}{c}\text { COMPRIMENTO } \\
(\mathrm{m})\end{array}$ & $\begin{array}{c}\text { RDE } \\
\text { TOTAL }\end{array}$ & $\begin{array}{c}\text { ANOMALIAS } \\
\text { DE 2 }{ }^{\circ} \text { ORDEM }\end{array}$ & $\begin{array}{c}\text { ANOMALIAS } \\
\text { DE 1 ORDEM }\end{array}$ \\
\hline Rio São João & 780 & 12331 & 195,6 & 13 & 3 \\
\hline Córrego Água Fria & 580 & 5754,7 & 159,57 & 6 & 1 \\
\hline Ribeirão Tabuão & 220 & 13210 & 58,25 & 2 & - \\
\hline Rio Grão Mogol & 800 & 13093,1 & 194,64 & - & - \\
\hline Córrego Grande & 640 & 7329,1 & 160,62 & 11 & - \\
\hline Córrego Mocotó & 540 & 8133,29 & 143,22 & 17 & - \\
\hline Rio Sem Nome & 500 & 5106,5 & 129,73 & 13 & 12 \\
\hline Rio do Salto & 880 & 26102,6 & 204,08 & 13 & - \\
\hline Córrego do Turma & 580 & 5663,3 & 160 & 3 & - \\
\hline Rio Pedra Branca & 280 & 8276,1 & 76,72 & 4 & - \\
\hline Rio Rosa Gomes & 420 & 22139,2 & 101,38 & 3 & - \\
\hline Ribeirão da Cata & 320 & 17767 & 84,9 & 4 & - \\
\hline Ribeirão Pari & 740 & 18371 & 178,4 & 18 & 7 \\
\hline Córrego Garra & 360 & 5365,83 & 129,73 & & \\
\hline
\end{tabular}

É característica na área de estudo, diga-se de passagem, a intercalação de segmentos em encaixamento pronunciado com extensões de estocagem sedimentar, sugerindo a existência de blocos em soerguimento e subsidência, que ora favorecem o entalhe vertical e o transporte, ora a retenção de sedimentos. Tais processos, tal como os trechos de epigenia, implicam em rupturas no perfil longitudinal dos canais, elevando, por vezes abruptamente, os valores de RDE.

Cursos d'água importantes na região das altas cristas quartzíticas, como o ribeirão do Pari, têm seus valores de RDE elevados quando dissecam as frentes escarpadas, o que pode ser considerado previsível em função da natural energia do relevo nos taludes e escarpas talhados no quartzito e preservados em função de aspectos estruturais, no caso a resistência diferenciada do referido metassedimento que implica em erosão diferencial francamente assinalada em relação às superfícies adjacentes emolduradas em xistos e gnaisses. No entanto, pode-se considerar a vigência de esforços deformacionais ativos na manutenção destes alinhamentos em permanente reativação, o que engendra, inclusive, patamares reafeiçoados em interflúvios e escalonamento bem marcado dessas estruturas, além de facetamentos trapezoidais e anfiteatros suspensos. Tal padrão atinge máxima grandiloquência no rio do Salto, que apresenta o maior número de anomalias de primeira ordem entre os canais para os quais o índice RDE foi mensurado. Em grande parte, tais anomalias são estabelecidas nas vertentes escarpadas que se projetam a jusante de uma planície alveolar altimontana formada quando o canal vence a soleira. A maior parte das rupturas e modificações abruptas no fundo do vale encontra apontamento no mapa de superfícies de base (Figura 3) pela aproximação das isobases, sendo o rio do Salto altamente representativo desse tipo de comportamento ao perpassar a escarpa de falha e degraus reafeiçoados da Serra do Ibitipoca. Não é diferente a configuração em referência aos rios Pari, São João e Monte Verde. 


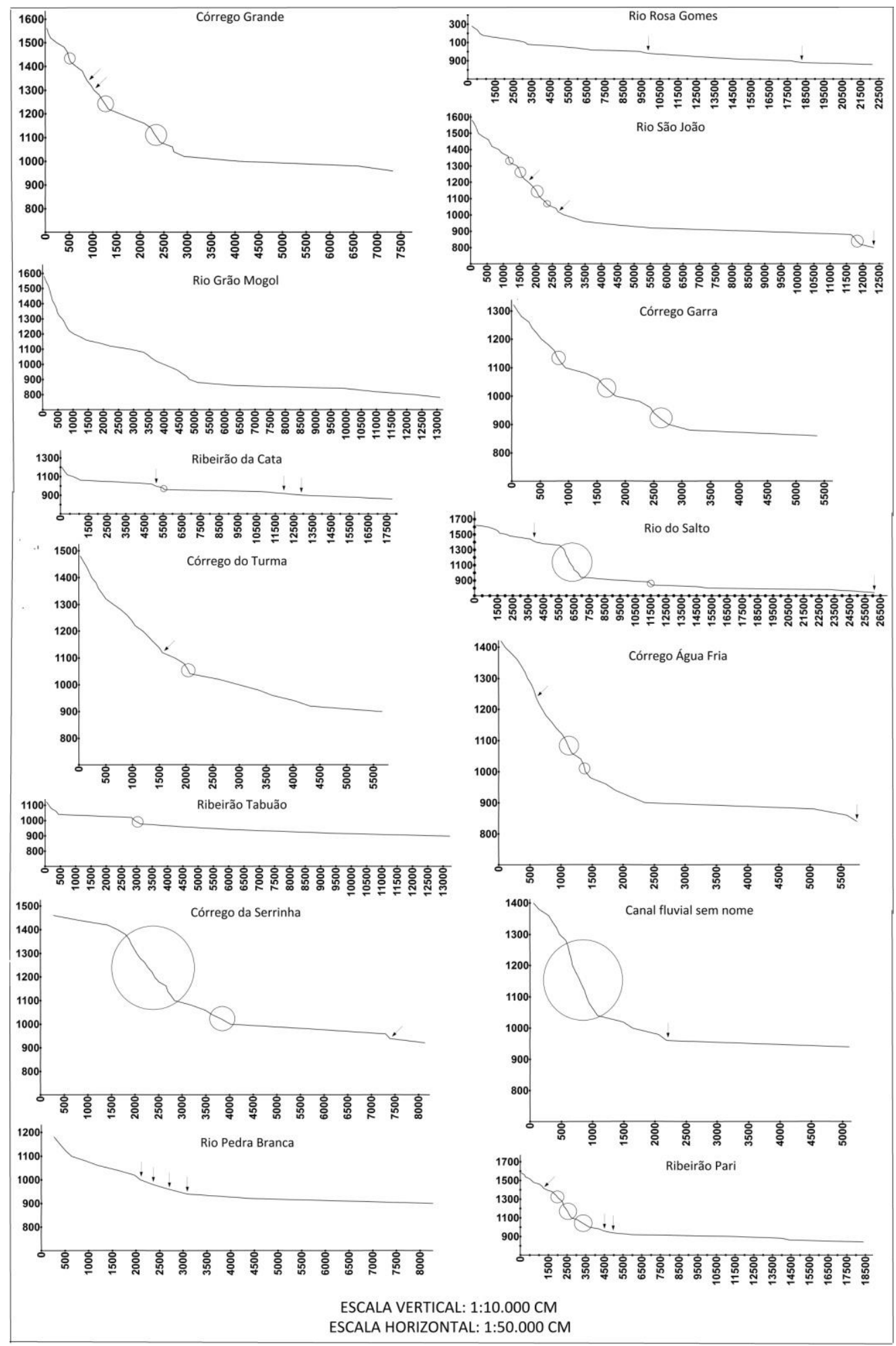

Figura 2: Perfis longitudinais dos canais fluviais estudados. 


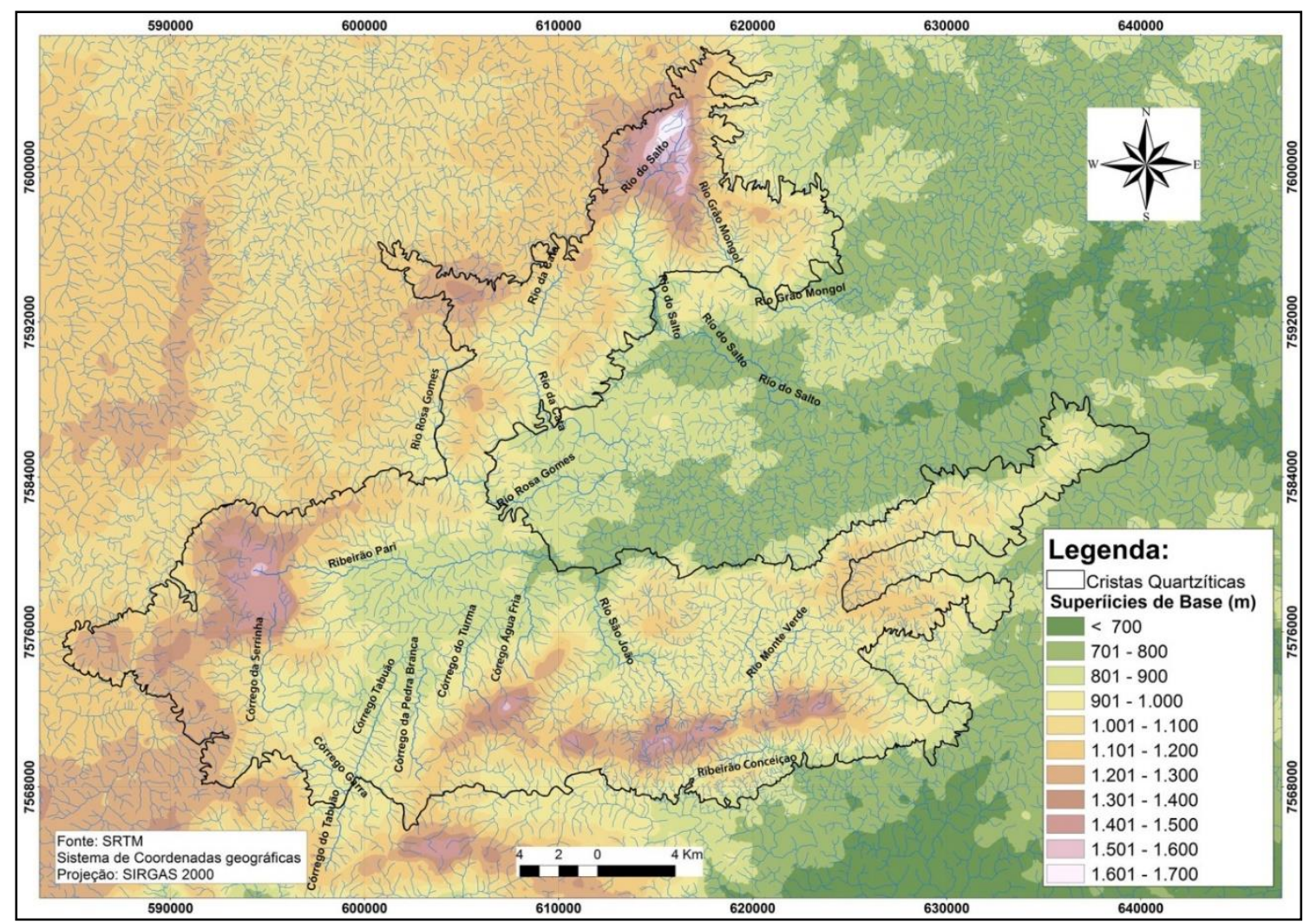

Figura 3: Superfícies de base mensuradas para a área de estudo e adjacências.

Em suma, os canais cujas cabeceiras estão posicionadas nas altas vertentes das cristas quartzíticas apresentam valores elevados de RDE no alto curso. Além dos retrocitados, outros podem ser enumerados: córrego Mocotó, córrego São João, córrego da Água Fria, rio São João, etc. Ainda que um controle morfotectônico nesses segmentos seja verossímil, o arranjo da drenagem nessas estruturas preexistentes é latente. No entanto, comportamentos anômalos também são copiosamente verificados no médio e baixo curso destes canais, com aumentos bruscos na energia da corrente precedidos por extensões nas quais o canal apresenta baixo gradiente, conforme apontado pelo RDE.

O rio do Salto, a exemplo do que foi acima frisado, apontou valores elevados na faixa de 860 metros de altitude, quando as escarpas de falha são transpostas e o canal sofre novo encaixamento, passando a dissecar um patamar escarpado mais baixo que estabelece contato com os compartimentos intermontanos de dissecação mais homogênea, onde uma planície estreita se desenvolve na faixa dos 800 metros de altitude, que sofre pronunciado estreitamento abaixo de 740 metros, quando se desenvolve um nível mais baixo de planície fluvial a preceder a afluência no rio do Peixe, fenômeno visivelmente ligado a uma shutter ridge bem marcada por falha transcorrente. Os diferentes níveis de planície também coincidem com aproximação das isobases, mostrando que os principais escalonamentos do rio do Salto correspondem a níveis de base locais provavelmente vinculados a blocos distintos em franca movimentação.

Outros canais também apresentam mais de um nível de planície fluvial, tal como o ribeirão da Cata, que apresenta um nível mais altimontano pouco acima de 1000 metros que é suprimido por mudança abrupta da direção NE-SW para NW-SE que acompanha o deslocamento de seu divisor provocado por falha transcorrente, determinando encaixamento abrupto do canal. Doravante, pouco acima dos 900 metros são desenvolvidos alvéolos de largura irregular que precedem novo desvio seguido de desnivelamento e encaixamento. Nos setores intermontanos foi constatada tendência de estrangulamento abrupto ou formação de novos níveis de planícies fluviais na faixa altimétrica de 900 a 940 metros, conforme verificado, além do ribeirão da Cata, no córrego da Água Fria e no córrego da Serrinha.

Os padrões estabelecidos podem ser correlacionados a níveis de base locais, desnivelados tectonicamente em relação ao rio do Peixe, que estabelece um importante nível de base regional na faixa dos 700 metros, na qual sua planície fluvial é significativamente desenvolvida e precede o escalonamento à jusante que o coloca em afluência no rio Preto, tronco coletor de maior grandeza e afluente direto do rio Paraíba do Sul. Níveis de base altimontanos na forma de pequenos vales suspensos e não detectáveis na escala trabalhada são feições de cunho morfotectônico bastante conspícuas nas altas cristas. 
Os contatos litológicos mais contrastantes estabelecidos entre quartzitos e gnaisses são discordantes à orientação dos principais canais, e mesmo o rio do Peixe, originalmente controlado pelas estruturas quartzíticas, apresenta inflexões e encaixamentos abruptos em um mesmo contexto litológico, somando mais uma evidência de controle tectônico. A maior parte das feições discutidas, como abertura, estrangulamento e desnivelamento de planícies fluviais, sinalizadas pelo RDE e pela mensuração das superfícies de base, bem como as inflexões dos canais, muitas vezes associadas a falhas transcorrentes, não estão ligadas a contatos litológicos, mas a basculamentos levados a efeito em falhas ativas em um mesmo domínio litológico. Não havendo uma correlação positiva entre tais fatos geomórficos e os contatos litológicos, defende-se que são majoritariamente morfotectônicos, o que é corroborado por outras evidências encontradas na área (terraços deformados, vales suspensos, migração lateral de canais com assimetria de bacias de drenagem, etc.). Exceção digna de nota é o rio Grão Mogol, único curso d'água que não apresentou nenhum valor anômalo de RDE; disseca, dominantemente, gnaisses tonalíticos adaptado a uma zona de cisalhamento designada por Heinek et al. (1991) como Zona de Cisalhamento Chapeu d'Uvas, em contraste às evidências conspícuas no conjunto dos demais canais investigados.

\section{CONCLUSÃO}

Sumarizando os resultados que foram apresentados e discutidos, e amarrando aos mesmos alguns pontos conclusivos, depreende-se que: (A) As técnicas referidas pelo índice RDE e pela mensuração e representação das superfícies de base apresentam complementaridade e admitem uma abordagem dialógica em estudos pautados na geomorfologia tectônica; (B) Nem sempre valores elevados de RDE configuram de fato anomalias, havendo a necessidade de se diferenciar os comportamentos verdadeiramente anômalos tectonicamente controlados daqueles ligados às estruturas passivas; (C) A área de estudo congregou uma série de evidências de tectônica ativa, algumas delas detectáveis pelas técnicas aqui apresentadas, determinando a existência de significativo controle morfotectônico sobreposto às estruturas preexistentes, bastante contundentes na evolução cenozoica do relevo e influentes nas organizações mais recentes dos sistemas geomorfológicos afetados.

\section{REFERÊNCIAS}

CHIESSI, C. M. Tectônica Cenozoica no Maciço Alcalino de Passa Quatro (SP-MG-RJ). Dissertação (Mestrado em Geologia). Instituto de Geociências, Universidade de São Paulo, São Paulo, 2004.

ETCHEBEHERE, M. L. C. Terraços Neoquaternários no Vale do Rio do Peixe, Planalto Ocidental Paulista: implicações estratigráficas e tectônicas. Tese (Doutorado em Geociências) - Instituto de Geociências e Ciências Exatas, Universidade Estadual Paulista. Rio Claro, 2000. 264p

ETCHEBEHERE, M.L.C.; SAAD, A.R.; FULFARO, J.V.; PERINOTO, J.A.J. Aplicação do índice "relação declividade-extensão - RDE" na Bacia do Rio do Peixe (SP) para deteç̧ão de deformações neotectônicas. Revista do Instituto de Geociências, USP. Série Científica, v. 4, n. 2, p. 43-56, 2004

FACINCANI, E. M. Morfotectônica da Depressão Periférica Paulista e cuesta basáltica: regiões de São Carlos, Rio Claro e Piracicaba, SP. Tese (Doutorado em Geologia Regional) - Instituto de Geociências e Ciências Exatas, Universidade Estadual Paulista. Rio Claro, 2000. 222p.

FERREIRA, M. F. M. Geomorfologia e análise morfotectônica do alto vale do Sapucaí. Tese (Doutorado em Geociências e Meio Ambiente). Instituto de Geociências e Ciências Exatas, Universidade Estadual Paulista, Rio Claro, 2001. 279p.

GATTO, L. C. S.; RAMOS, V. L. S.; NUNES, B. T. A.; MAMEDE, L.; GÓES, M. H. B.; MAURO, C. A.; ALVARENGA, S. M.; FRANCO, E. M. S.; QUIRICO, A. F.; NEVES, L. B. Geomorfologia. In: Projeto RADAMBRASIL. Folha SF-23/24 Rio de Janeiro/Vitória. Rio de Janeiro: IBGE, 1983.

GONTIJO, A. H. F. Morfotectônica do médio vale do Rio Paraíba do Sul: região da Serra da Bocaina, estados de São Paulo e Rio de Janeiro. Tese (Doutorado em Geologia). Instituto de Geociências e Ciências Exatas, Universidade Estadual Paulista. Rio Claro, 1999. 259p.

HACK, J. T. Stream-profile analysis and stream-gradient index. Journal of Research of United States Geological Survey. v. 1, n. 4, p. 421-429, 1973. 
HEINEK, C. A.; SOUZA, H. A.; VASCONCELOS, R. M.; BARRETO, E. L.; GOMES, R. A. A. D.; PINTO, C. P. Programas Levantamentos Geológicos Básicos do Brasil. Companhia de Pesquisa de Recursos Minerais. Folha SF.23-X-C-VI, 1991.

HIRUMA, S. T; RICCOMINI, C. Análise morfométrica em neotectônica: o exemplo do Planalto de Campos do Jordão. Revista do Instituto Geológico, São Paulo, USP, v. 20, n. 1⁄2, p. 5-19, 1999.

JAIN, V.E. Geotectónica general. 2. ed. Moscou: Mir Ed., 1984.

MARQUES NETO, R. Estudo evolutivo do sistema morfoclimático e morfotectônico da bacia do Rio Verde (MG), sudeste do Brasil. Tese (Doutorado em Geografia). Instituto de Geociências e Ciências Exatas, Universidade Estadual Paulista, Rio Claro, 2012. 430p.

MORALES, N. Neotectônica em ambiente intraplaca: exemplos da região Sudeste do Brasil. Rio Claro, Tese (Livre Docência em Geologia Estrutural e Geotectônica), Instituto de Geociências e Ciências Exatas, Universidade Estadual Paulista. 2005. 201p.

RIBEIRO, M. C. S. História tectônica e exumação das serras da Bocaina e Mantiqueira, SP/RJ. Dissertação (Mestrado em Geologia Regional), Instituto de Geociências e Ciências Exatas, Universidade Estadual Paulista, Rio Claro, 2003. 124p.

RICCOMINI, C. O rift continental do sudeste do Brasil. São Paulo. Tese de Doutorado, Instituto de Geociências, Universidade de São Paulo. 1989. 256p.

RICCOMINI, C.; SANT’ANNA, L. G.; FERRARI, A. L. Evolução geológica do Rift Continental do Sudeste do Brasil. In: MANTESSO-NETO, V. BARTORELLI, A.; CARNEIRO, C. D. R.; BRITO NEVES, B. B. (Org.) Geologia do Continente Sul-Americano: evolução da obra de Fernando Flávio Marques de Almeida. São Paulo: Beca, 2004. P. 407-421.

SAADI, A. Ensaio sobre a morfotectônica de Minas Gerais: tensões intraplaca, descontinuidades crustais e morfogênese. Belo Horizonte. Tese (Professor Titular), Instituto de Geociências, Universidade Federal de Minas Gerais. 1991. 285p.

SALVADOR, E. D; PIMENTEL, J. Avaliação da neotectônica no município de Angra dos Reis, setor sulfluminense da Serra do Mar, com base em mapas morfométricos gerados em Sistemas de Informações Geográficas (SIG). In: SIMPÓSIO BRASILEIRO DE SENSORIAMENTO REMOTO, 14., 2009, Natal. Anais... Natal: INPE, 2009. p. 3347-3354.

SANTOS, M. Serra da Mantiqueira e Planalto do Alto Rio Grande: a bacia terciária de Aiuruoca e evolução morfotectônica. Rio Claro. Tese (Doutorado em Geociências) - Instituto de Geociências e Ciências Exatas, Universidade Estadual Paulista. 1999. 134p.

SEEBER, L.; GORNITZ, V. River profiles along the Himalayan arc as indicators of active tectonics. Tectonophysics, v. 92, p. 335-367, 1983

SILVA, T. P.; MELLO, C. L. Reativações neotectônicas na Zona de Cisalhamento do Rio Paraíba do Sul (sudeste do Brasil). Revista do Instituto de Geociências, v. 11, n. 1, p. 95-111, 2011.

SOARES, A. C. P; NOCE, C. M; TROUW, R. A. J; HEILBRON, M. Projeto Sul de Minas. COMIG-UFMGUFRJ-UERJ, 2002.

STRAHLER, A. N. Dynamic basis of geomorphology. Geological Society of American Bulletin, v. 63, p. 923-938, 1952. 